\title{
Simulation of senescence and disappearance rates in irrigated and dryland pastures ${ }^{1}$
}

\author{
R.F. ZYSKOWSKI, E.S. BURTT, T.J. FRASER* and A.C. BYWATER \\ Department of Farm \& Horticultural Management, Lincoln University \\ *AgResearch, PO Box, 60, Lincoln
}

\begin{abstract}
Previous experiments with a sheep farm grazing model suggested a weakness in assumptions concerning pasture senescence and disappearance rates which was influencing the quantity and more importantly quality of pasture on offer and hence animal performance. Data from the Winchmore Research Station describing pasture masses and the amount of dead material in irrigated swards over several years have been used to derive joint estimates of growth and senescence rates and produced patterns similar to the few data available in the literature. Subjective estimates were made of likely differences in senescence between dryland and irrigated conditions and the model used to simulate the implications of these assumptions. Results demonstrate the sensitivity of animal performance to assumptions about the senescence and disappearance rates of pasture, particularly in the dryland situation where previously unrealistically high levels of performance were reduced closer to expected levels. This reinforces the desirability of collecting data on dead material in trials involving pasture measurements. Pasture production, percentage harvested and animal performance estimates from the model are presented.
\end{abstract}

Keywords: Lolium perenne, pasture disappearance, pasture senescence, sheep grazing, simulation model, Trifolium repens

\section{Introduction}

There are far more experimental data on the rate at which pastures grow than there are on the rate at which they die. Yet both rates affect the quantity and quality of pasture available for grazing and therefore animal performance.

As part of a programme investigating high performance forage systems for sheep production, simulation analyses using LincFarm, a sheep farm model

1 This work was supported by FRST contract number PGSF96AGR-01-5221. The authors wish to acknowledge the assistance of an anonymous reviewer. described by Cacho et al. (1995), are being used in parallel with irrigated and dryland farmlet trials conducted by AgResearch at the Winchmore research station.

LincFarm estimates of production from ryegrasswhite clover control treatments were conducted at three stocking rates $(10,12$ and $15 \mathrm{su} / \mathrm{ha}$ for dryland and 15, 17 and $20 \mathrm{su} / \mathrm{ha}$ for irrigated), each replicated three times. Mean results from the intermediate stocking rates were compared with target performance on the trial farmlets and earlier Winchmore data (Moss 1987) and are shown in Table 1 (Bywater 1996 pers. comm.). Results from simulations of the irrigated farmlet were intermediate between the target and the data from Moss. Those from the dryland simulations over-predicted ewe production and resulted in unrealistically high lambing performance for this situation, especially given the fact that target performance is based on the assumption that ewe body weight at tupping will be maintained through supplementary feeding if required, whereas there is no supplementation in the model. There may be a number of reasons for the over-prediction but the most likely explanation is that some pasture parameters, particularly those related to pasture senescence, disappearance and quality, were not appropriate to describe dryland pastures.

The only difference between parameters describing the irrigated and dryland situations was in potential relative growth rates. Owing to a lack of published data, senescence and litter disappearance rates (percentage/ day) were set the same for dryland as for irrigated pastures, as were parameters determining intake and pasture quality. The net result is that in the simulations referred to above, although pasture growth rates may have been appropriate to the dryland situation, it seems likely that the quality of feed consumed by the animals, and therefore the amount consumed, was much higher in the model than might be expected in reality. This, plus the lower stocking rates on dryland pastures, resulted in significantly higher ewe body weights, particularly at mating and over winter, leading to the elevated lambing percentages shown in Table 1.

Estimates of pasture mass and the percentage dead material in the sward at 2-weekly intervals also indicated that seasonal patterns of senescence and decay rates were not well specified for the two situations. We expect that the percentage dead would be higher in dryland 
conditions in summer and lower in winter than under irrigation. This implies that senescence rates will be higher from November to April for dryland than for the irrigated situation, while disappearance rates are likely to be lower.

Given the above results, it was decided to investigate senescence and disappearance further to see if the model parameters could be improved.

\section{Senescence}

Senescence and decay rates of pastures used in the original simulations are as reported by Cacho et al. (1995). The original senescence rate pattern for irrigated pastures is shown as the continuous line in Figure 1. Both in New Zealand and overseas very few data sets have been published dealing with senescence of ryegrass-based swards. In New Zealand, Hunt (1970, 1971) reports data on the death rate of leaves in ryegrass-white clover swards during 80 days of regrowth in both spring and autumn collected at 2- and 4-day intervals respectively. Senescence rates are shown in Figure 1.

Data from Hunt show considerable variation but no clear difference in senescence between spring and
Table 1 LincFarm estimates of production on Winchmore forage systems farmlets (Bywater et al. 1996 pers. comm.) compared with target performance (AgResearch estimates) and earlier Winchmore data (1981 to 1985) of Moss (1987).

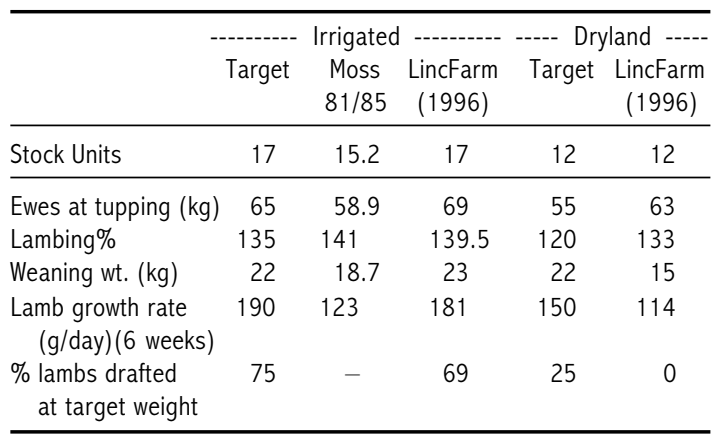

autumn, and do not provide a pattern of senescence over the year. Subsequent work by Hunt (1983) provides data on senescence rates $(\mathrm{kg} / \mathrm{ha} / \mathrm{day})$ of Grasslands Ruanui and Grasslands Nui ryegrasses over 3 years, but we have been unable to convert these to percentage rates owing to the lack of data on pasture mass. The

Figure 1 Original senescence rate (Cacho et al. 1995), data sets from the literature and recalculated senescence rate (percentage/ day).

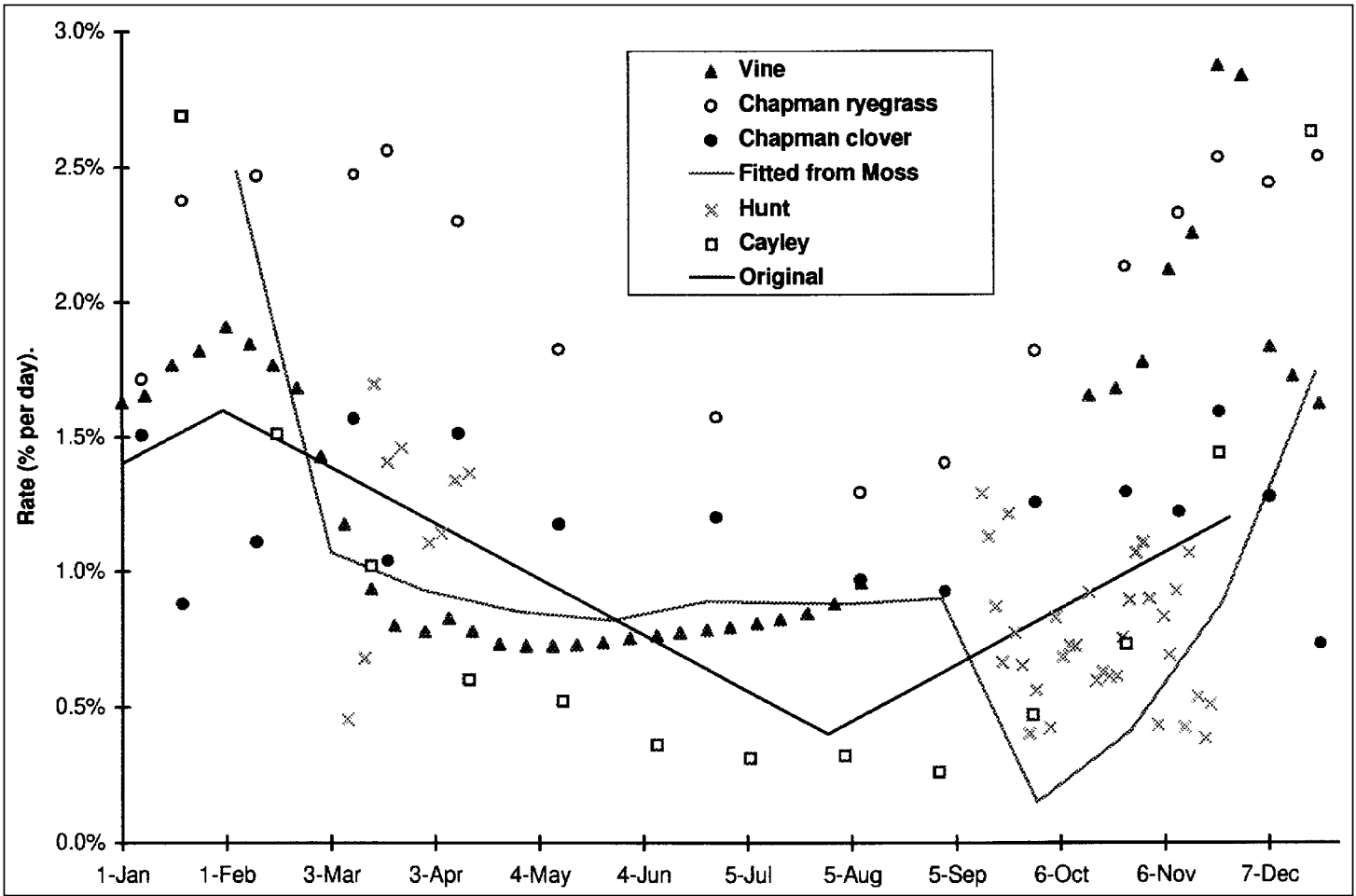


three most comprehensive data sets we have been able to find are those of Chapman and Clark in New Zealand (Chapman et al. 1984; Clark et al. 1984), Vine in Scotland (Vine 1983) and Cayley et al. (1980) in Australia. In a hill country grazing trial at the Ballantrae Research Station, Chapman et al. (1984) described leaf death rates in perennial ryegrass, white clover and browntop over a 12-month period (March to March). Data on the leaf death rate (leaves per tiller per day) are given for each of the three pasture species. Percentage senescence rates for ryegrass and white clover have been calculated by relating these data to data on leaf numbers per tiller reported by Clark et al. (1984). The resulting estimates are shown in Figure 1.

Vine (1983) measured leaf life-span in ryegrass swards subject to various nitrogen treatments in Scotland. Senescence rate has been calculated by taking the reciprocal of the life-span and these estimates are also shown in Figure 1 adjusted to a Southern Hemisphere calendar. Also in Figure 1 are senescence rates calculated from data on ryegrass-subterranean clover pastures from Cayley et al. (1980) in Hamilton, Victoria, and these show a somewhat similar pattern to that of Vine. Bowman et al. (1982) showed from the latter data that the principal cause of variation in senescence is moisture stress as indicated by declining soil moisture.

The general pattern of these sets of data is similar, with high levels of senescence in late spring-summer and lower levels in winter. The Vine data provide a clearer pattern, with a sharp fall in senescence in autumn, a plateau over winter and a rapid rise during late spring towards a mid- to late-summer peak. Data are not available for the early spring period. Data from Chapman et al. show a higher rate than those of Vine or Cayley et al. except in early summer, but it seems reasonable that senescence rates in hill country would be higher than in easier country.

None of these sources of data are from environments similar to the Canterbury Plains, so that while they provide some indication of the pattern of senescence over the year, they do not estimate the actual rates. As shown later, these have been deduced from data from Winchmore.

\section{Litter disappearance}

Data on the rate of disappearance of dead material from grazed swards are even more sparse than for senescence. The assumption in the model is that disappearance peaks in mid winter at $5 \%$ with a minimum in mid summer of $2 \%$ and a straight line interpolation between the two (Cacho et al. 1995). Three main processes are responsible for disappearance of dead herbage: worm action, microbial decay and physical disintegration through trampling (McCall 1984). Sharpley et al. (1979) have shown that based on worm casts but not litter disappearance per se, worms are most active in early winter, and least active in spring. Fraser, P.M. (1997 pers. comm.) has shown that there is little difference in the disappearance rate of litter when worms have access to litter or are excluded from it, indicating that both microbes and worms remove litter at approximately the same rate down to about $30 \%$ of original mass (indicating perhaps the limit of microbial degradation). In Australia, Cayley et al. (1980) show disappearance rates that average approximately $1.3 \%$ and are relatively constant over winter, falling quite quickly in August to a rather less constant rate averaging around $0.5 \%$ in spring and summer, rising again in April. Analysing these data, Bowman et al. (1982) concluded that disappearance was related to rainfall with a 2-week delay, which they associated with a build-up of decomposer populations. Hunt (1983) presents data on litter disappearance (\% per day) for Ruanui and Nui ryegrass which indicate that the rate of disappearance peaks in autumn falling to a low in late spring. Although there are data on the effects of trampling on pasture growth rates (e.g., Brown \& Evans 1973), there are none that the authors are aware of on effects on litter disappearance.

McCall (1996 pers. comm.) has suggested that in New Zealand, litter disappearance in total is higher in winter at approximately $5 \%$ and drops during spring to perhaps half that value over summer. In the absence of any other data, litter disappearance under irrigation is assumed to follow the same pattern shown by Cayley et al. (1980), with a value of 5\% from day 101 (April 11) to 245 (September 2) and 3\% for the remainder of the year.

\section{Estimating growth and senescence rates}

In his account of experimental data from Winchmore, Moss (1987) provides summary data on the amount of dead material in irrigated swards for 3 years. Based on the original data from which these summaries were made (Moss 1997 pers. comm.), plus 20 years of green pasture masses from cutting trials (Rickard \& McBride 1986), a combined data set has been collated from which estimates of various rates can be deduced for irrigated pastures. To begin with, the pasture model component of LincFarm was used to investigate the sensitivity of different assumptions about the pattern and value of both senescence and disappearance rates on the percentage of dead material in the sward over the year and its coincidence to the average values observed by Moss (1987). As expected, the pattern of dead material 
in the sward is sensitive to both the patterns and values of senescence and disappearance rates as well as to pasture growth rate.

With the pasture model used in LincFarm, given a data set containing green mass (or total mass) plus dead mass, it is possible to estimate two of these three rates simultaneously (i.e., two of growth, senescence and disappearance rates). On that basis, disappearance rate was set as described above (5\% over winter, $3 \%$ otherwise) and joint non-linear least squares estimates derived for both the growth rate parameter, alpha (see Cacho et al. 1995), and senescence rate. The resulting senescence rate pattern is shown in Figure 1 for comparison with the data discussed above. The estimated pattern of senescence rate is very similar to that calculated from the data of Vine (1983) over autumn and winter but the estimated value drops significantly in early spring when there are no data from Vine. During the remainder of spring and early summer, the estimated rate is more similar to the data from Cayley et al. (1980) in Australia. It seems likely that senescence expressed as a first order rate would drop during the period of rapid growth in spring. The data from Vine show senescence rates during early summer that are closer to those from Chapman et al. (1984) on hill country. Both increase during this period approximately $6-8$ weeks earlier than the fitted estimates. All three are similar in late summer.

As far as we are aware, there are no equivalent data to that above from which to estimate senescence and disappearance rates for dryland conditions. Based on the earlier discussion and the findings of Bowman et al. (1982) with respect to the influence of moisture stress, we have assumed that senescence rates on dryland pastures will increase faster and reach a maximum sooner in summer than under irrigation but will be approximately the same from autumn through to early spring. On this basis, senescence has been set to reach a peak of $3 \%$ in mid November; the winter rate is assumed to be the same as for irrigated pastures and the spring and autumn rates are calculated by interpolating between the early summer peak and the inflection points in spring and autumn.

It is also assumed that owing to a lack of moisture during summer (the principal period of microbial decay) disappearance on dryland is half that in irrigated swards over that period; the assumed rate is reduced from $3 \%$ to $1.5 \%$ from day 330 (November 26) until the rate increases again to 5\% in April. Resulting growth and senescence rates are shown in Figure 2. The implications of the revised parameter estimates on pasture masses and animal performance are discussed in the next section.

\section{Simulation of pastures and animal performance}

The standard protocol adopted in this program is to run each treatment on LincFarm at three stocking rates for both dryland and irrigated pastures, with three replicates, each for 10 years. The first four years of each run are discarded, leaving 6 years' results. Except where noted, the results presented here are the mean (over years and replicates) for the intermediate stocking rate for each environment.

Pasture cover data (Figure 3) are the pre-grazing pasture mass (green and dead) plus the percentage dead material on the break grazed by the ewes on the date shown. Peak amount and percentage of dead material occur in late February in the irrigated pasture with a maximum of $34 \%$ dead; dead material accumulates much earlier and to a higher level in the dryland situation, reaching $69 \%$ by February. Over the whole year, harvest percentage, the total amount of pasture consumed as a proportion of the total amount grown each month, is higher for the irrigated system because of the higher stocking rate and better match between feed supply and demand (Table 2).

Table 2 Average pasture growth rates, production and harvested percentage per month using revised parameter estimates for irrigated (17 su/ha) and dryland (12 su/ha) systems.

\begin{tabular}{|c|c|c|c|c|c|c|}
\hline & $\begin{array}{c}\text { Daily } \\
\text { growth } \\
\text { (kg/day) }\end{array}$ & $\begin{array}{l}\text { - Irrigated } \\
\text { Monthly } \\
\text { production } \\
\text { (kg DM) }\end{array}$ & $\begin{array}{c}\text { Harvest } \\
\%\end{array}$ & $\begin{array}{c}\text { Daily } \\
\text { growth } \\
\text { (kg/day) }\end{array}$ & $\begin{array}{l}\text { - Dryland } \\
\text { Monthly } \\
\text { production } \\
\text { (kg DM) }\end{array}$ & $\begin{array}{c}------ \\
\text { Harvest } \\
\%\end{array}$ \\
\hline January & 59 & 1835 & 56 & 22 & 696 & 32 \\
\hline February & 47 & 1310 & 57 & 11 & 356 & 34 \\
\hline March & 37 & 1159 & 51 & 17 & 526 & 28 \\
\hline April & 21 & 615 & 107 & 11 & 345 & 37 \\
\hline May & 12 & 374 & 136 & 9 & 294 & 50 \\
\hline June & 8 & 228 & 130 & 6 & 180 & 103 \\
\hline July & 7 & 214 & 69 & 6 & 186 & 82 \\
\hline August & 7 & 232 & 29 & 9 & 293 & 70 \\
\hline September & 35 & 1036 & 51 & 36 & 1127 & 50 \\
\hline October & 63 & 1965 & 63 & 63 & 1940 & 43 \\
\hline November & 61 & 1842 & 80 & 39 & 1199 & 55 \\
\hline December & 60 & 1859 & 75 & 28 & 860 & 56 \\
\hline Average & & & 76 & & & 53 \\
\hline Total & & 12669 & & & 8002 & \\
\hline
\end{tabular}

The animal performance data (Table 3), which includes data from Table 1 plus the results from the model for each stocking rate with the revised pasture parameters. No other parameters have been changed, so that the results illustrate the effect of different 
Figure 2 Growth (from eqtn 1 of Cacho et al. 1995) and senescence rates with revised parameter estimates for Irrigated (A) and Dryland (B) pastures.

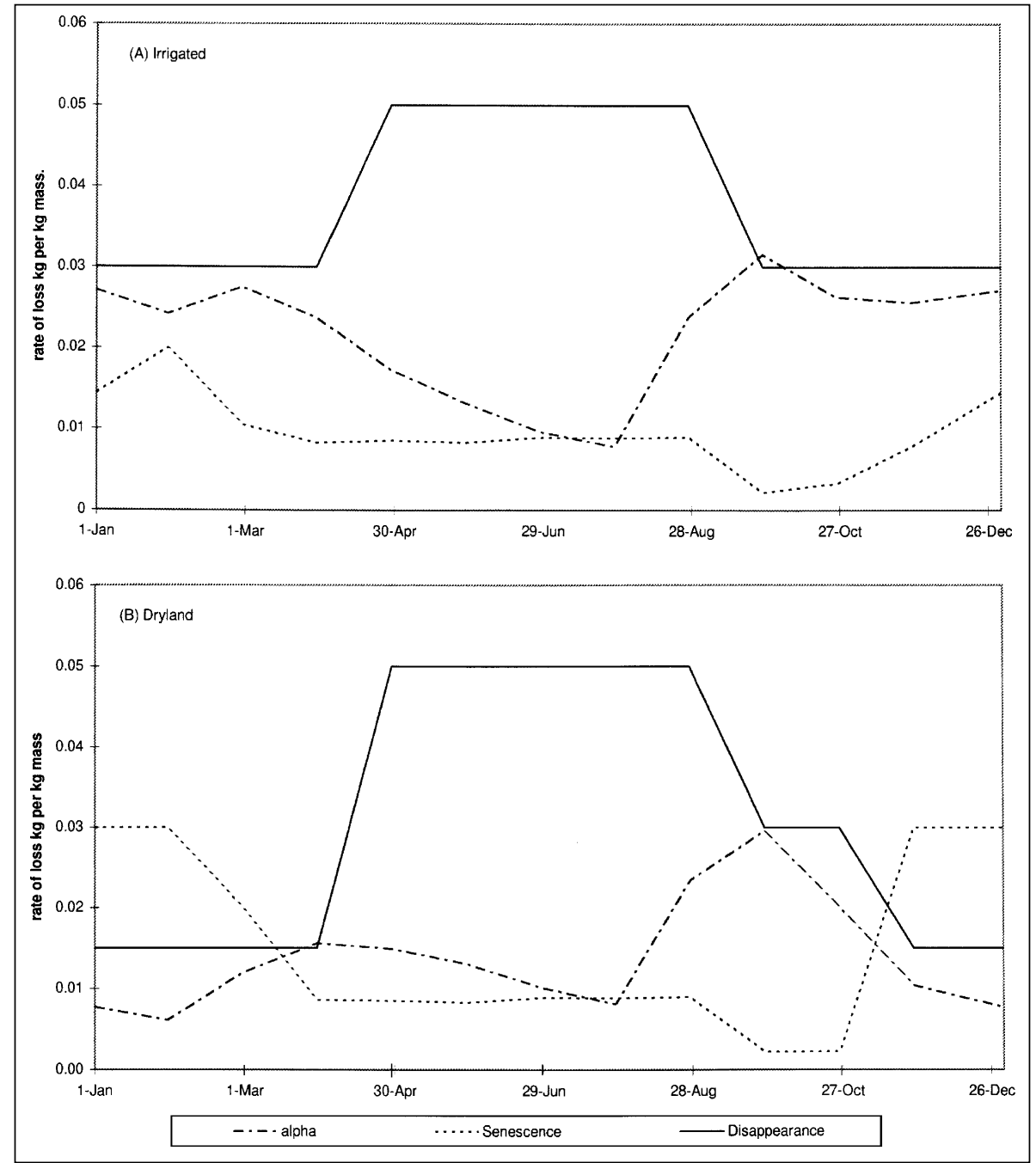

Table 3 LincFarm estimates of animal performance for irrigated and dryland systems at the three stocking rates (15, 17 and 20 s.u. per ha irrigated and 10,12, 15 su/ha dryland) using revised pasture parameters, compared with original estimates (Bywater et al. 1996 pers. comm.).

\begin{tabular}{|c|c|c|c|c|c|c|c|c|c|c|c|c|c|c|c|c|c|}
\hline \multirow[b]{2}{*}{ Stock units } & \multicolumn{3}{|c|}{---- Original ---- } & \multirow{2}{*}{$\begin{array}{l}\text { Irrigated } \\
\text { Target } \\
17\end{array}$} & \multicolumn{3}{|c|}{$\overline{\text {---- Revised ---- }}$} & \multicolumn{3}{|c|}{---- Original ---- } & \multirow{2}{*}{$\frac{\text { Target }}{12}$} & \multicolumn{6}{|c|}{$\begin{array}{l}\text { Dryland } \\
\text {---- Revised ---- -- Supplemented -- }\end{array}$} \\
\hline & 15 & 17 & 20 & & 15 & 17 & 20 & 10 & 12 & 15 & & 10 & 12 & 15 & 10 & 12 & 15 \\
\hline Ewes at tupping (kg) & 71 & 69 & 66 & 65 & 70.2 & 67.3 & 62.3 & 62 & 63 & 67 & 55 & 50.9 & 47.8 & 45.5 & 57.1 & 56.5 & 55.4 \\
\hline Lambing\% & 139.5 & 139.5 & 136 & 135 & 139 & 138 & 131 & 134 & 133 & 126 & 120 & 105 & 101 & 101 & 115 & 116 & 114 \\
\hline Weaning wt. (kg) & 23 & 23 & 22 & 22 & 26 & 26 & 26 & 16 & 15 & 20 & 22 & 27 & 26 & 26 & 26 & 25 & 24 \\
\hline $\begin{array}{l}\text { Lamb growth rate } \\
\text { (g/day) (6 weeks) }\end{array}$ & 167 & 181 & 196 & 190 & 209 & 211 & 189 & 128 & 114 & 157 & 150 & 127 & 122 & 112 & 132 & 125 & 114 \\
\hline $\begin{array}{l}\% \text { lambs drafted } \\
\text { at target weight }\end{array}$ & 68 & 69 & 69 & 75 & 100 & 100 & 100 & 0 & 0 & 0 & 25 & 38 & 31 & 24 & 30 & 20 & 8 \\
\hline
\end{tabular}


Figure 3 Pasture covers (green and dead) and percentage dead on each grazing break, generated using the new parameter estimates for irrigated $(A)$ and dryland $(B)$ situations.
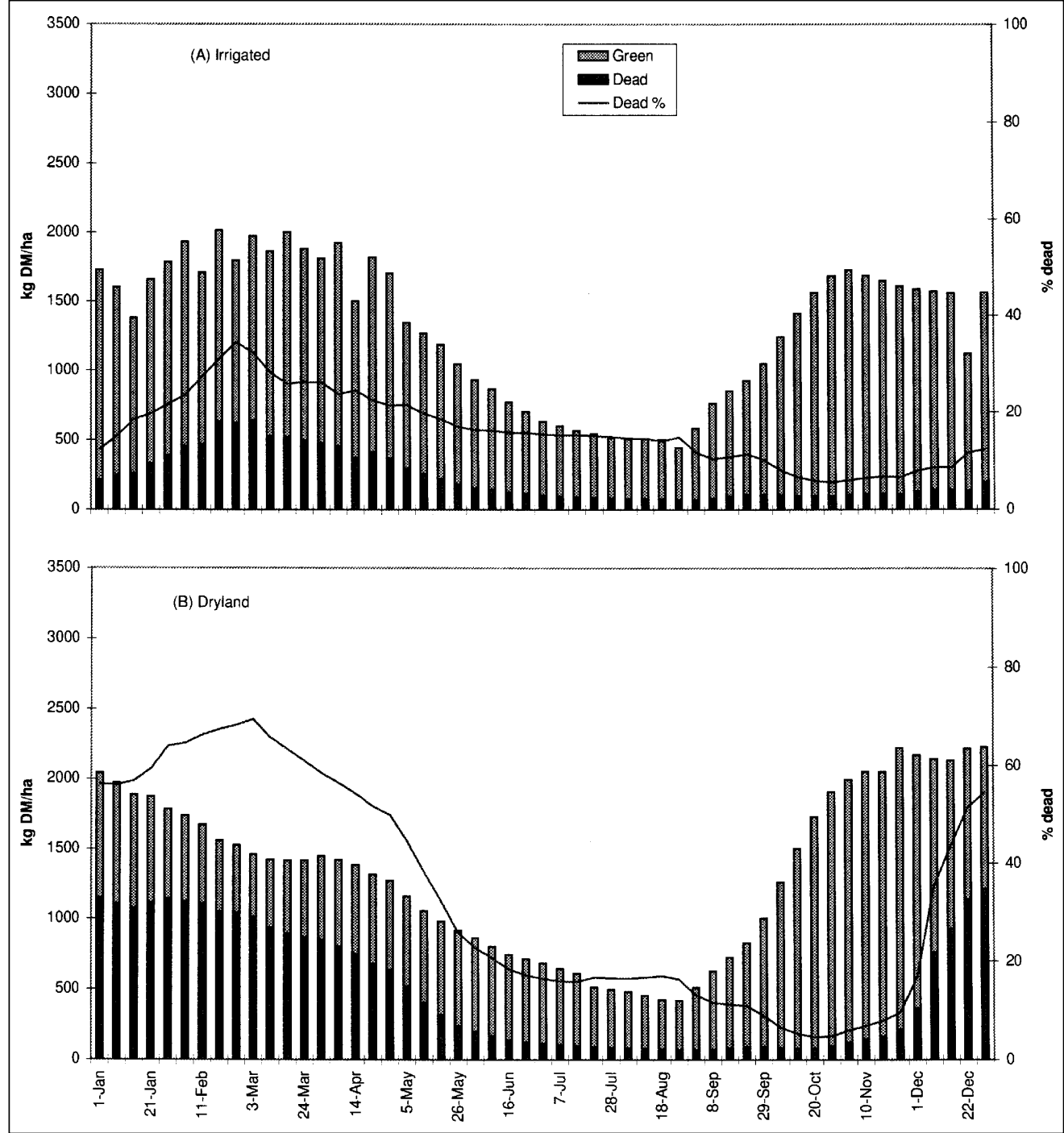

assumptions about senescence and disappearance rates only. In the irrigated situation, the revised pasture parameters result in slightly lower ewe body weights and lambing percentages, which are still intermediate between the reported results (Moss 1987) and the AgResearch targets. However, lamb performance, including weaning weight and post-weaning growth rates, are now higher than either the reported or target results; further work needs to be done to investigate the cause of this difference. In the dryland situation, the change in pasture parameters has resulted in a large reduction in ewe body weights at tupping, in lambing percentage and in lamb growth rates. The results for the intermediate stocking rate are now well below the targets, but this is not unreasonable since these runs have been made without supplementation of ewes before tupping to maintain body weight. Simulation of the dryland system with ewes supplemented with good quality hay over late summer to reach a target weight of $55 \mathrm{~kg}$ at tupping lifts performance to a level much closer to the results expected by AgResearch (Table 3, Supplemented).

Results from this research have demonstrated the sensitivity of animal performance to assumptions about 
the senescence and disappearance rates of pasture. This reinforces the desirability of collecting data on the amount of dead material in any trials involving pasture measurements so that these rates may be estimated.

\section{REFERENCES}

Bowman, P.J.; White, D.H.; Cayley, J.W.D.; Bird, P.R. 1982. Predicting rates of pasture growth, senescence and decomposition. Animal production in Australia 14: 36-38.

Brown, K.R.; Evans, P.S. 1973. Animal treading: A review of the work of the late D.B. Edmond. New Zealand journal of experimental agriculture 1: $217-$ 226.

Cacho, O.J., Finlayson, J.D.; Bywater, A.C. 1995. A simulation model of grazing sheep: II Whole farm model. Agricultural systems 48: 27-50.

Cayley, J.W.D.; Bird, P.R.; Chin, J.F. 1980. Death and decay rates of perennial pasture as affected by season. Proceedings of the Australian Society of Animal Production 13: 469.

Chapman, D.F.; Clark, D.A.; Land,C.A.; Dymock, N. 1984. Leaf and tiller or stolon death of Lolium perenne, Agrostis spp and Trifolium repens in setstocked and rotationally grazed hill pastures. New Zealand journal of agricultural research 27: 303312.

Clark, D.A.; Chapman, D.F.; Land, C.A.; Dymock, N. 1984. Defoliation of Lolium perenne and Agrostis spp tillers and Trifolium repens stolons in set-stocked and rotationally grazed hill pastures. New Zealand journal of agricultural research 27: 289-301.

Hunt, W.F. 1970. Influence of leaf death on the rate of accumulation of green herbage during pasture regrowth. Journal of applied ecology 7: 41-44.

Hunt, W.F. 1971. Leaf death and decomposition during pasture regrowth. New Zealand journal of agricultural research 14: 208-218.

Hunt, W.F. 1983. Nitrogen cycling through senescent leaves and litter of swards of Ruanui and Nui ryegrass with high and low nitrogen inputs. New Zealand journal of agricultural research 26: 461-471.

McCall, D.G. 1984. A systems approach to research planning for North Island hill country. PhD thesis, Massey University.

Moss, R.A. 1987. Pasture and animal performance on an irrigated sheep production farmlet. Technical Report 24, Winchmore Irrigation Research Station, $55 \mathrm{pp}$.

Rickard, D.S.; McBride, S.D. 1986. Irrigated and nonirrigated pasture production at Winchmore, 1960 to 1985. Technical Report 21, Winchmore Irrigation Research Station, 75 pp.

Sharpley, A.N.; Syers, J.K.; Springett, J.A. 1979. Effect of surface-casting earthworms on the transport of phosphorus and nitrogen in surface runoff from pasture. Soil biology and biochemistry 11: 459462.

Vine, D.A. 1983. Sward structure changes within a perennial ryegrass sward; leaf appearance and death. Grass and forage science 38: 231-242. 
